\title{
Reactive Solid-Phase Epitaxy: A Powerful Method for Epitaxial Film Growth of Complex Layered Oxides
}

\author{
Hiromichi OHTA*,**,*** \\ ${ }^{*}$ Graduate School of Engineering, Nagoya University, Furo-cho, Chikusa-ku, Nagoya-shi 464-8603 \\ **CREST, Japan Science and Technology Agency (JST), 4-1-8, Honcho, Kawaguchi-shi 332-0012 \\ ***ERATO-SORST, Japan Science and Technology Agency (JST), in Frontier Collaborative Research Center (FCRC), \\ S2-6F East, Mail-box S2-13, Tokyo Institute of Technology, 4259, Nagatsuta-cho, Midori-ku, Yokohama-shi 226-8503 \\ 反応性固相エピタキシャル成長法： \\ 層状複合酸化物の高品質エピタキシャル薄膜を作製するための強力な手法 \\ 太田裕道 $* * *, * * *$ \\ *名古屋大学大学院工学研究科, 464-8603 名古屋市千種区不老町 \\ **科学技術振興機構 CREST, 332-0012 川口市本町 4-1-8 \\ ***科学技術振興機構 ERATO-SORST，226-8503 横浜市緑区長津田 4259, S2-6F East, Mail-box S2-13 東京工業大学内
}

\begin{abstract}
High-quality epitaxial film growth for several complex oxides having layered structure by "Reactive Solid-PhaseEpitaxy (R-SPE ${ }^{1)}$ " is reviewed. Materials focused are $\operatorname{InGaO}_{3}\left(\mathrm{ZnO}_{m}(m=\right.$ integer$)$, $\mathrm{LaCuOS}$ and $\mathrm{Na}_{x} \mathrm{CoO}_{2}$ $(x \sim 0.8)$. For the epitaxial film growths of the complex systems with a complicated layered crystal structure, it is necessary to form an epitaxial template layer before the film deposition, followed by the thermal annealing of the bilayer films. The layers subsequently deposited on the template layer may be amorphous, polycrystalline or powder, which allows control of the epitaxially grown films in the R-SPE method.
\end{abstract}

[Received October 5, 2005]

Key-words : Reactive solid-phase epitaxy, Epitaxial film, Complex layered oxides, Natural MQW, Oxide electronics

\section{Introduction}

$\mathbf{C}^{\mathrm{s}}$ COMPLEX oxides with a multi-layered structure may exhibit exceptional properties originating from the spatial confinement of conductive electrons or holes in the twodimensional layer, which is similar to that in a multi-quantumwell (MQW) in semiconductors. Thus, such a structure may be regarded, in a sense, as a "natural MQW." Natural MQW is of great importance for the realization of next generation electronics; "oxide electronics." In order to fully utilize intrinsic potential of natural MQW, single-crystalline or high-quality epitaxial film of complex layered oxides is absolutely essential.

Generally, epitaxial films of semiconductors are fabricated by conventional vapor phase epitaxy (VPE) method such as RF-sputtering, ${ }^{2)}$ vacuum evaporation, chemical vapor deposition (CVD), molecular beam epitaxy $(\mathrm{MBE})^{3)}$ and pulsedlaser deposition (PLD) ${ }^{4}$ However, such VPE methods cannot be directly applied to the growth of complex oxides due to the fact described below: It is generally recognized in the vapor phase growth process that the two-dimensional Frank Van der Merwe growth mode, ${ }^{5)}$ which is necessary for the single-crystalline film growth, becomes dominant at temperatures higher than $\sim 60 \%$ of melting points of the compounds in question. Therefore, very high growth temperature $(>1000$ ${ }^{\circ} \mathrm{C}$ ) is required to grow single-crystalline films of oxides because of their high melting point $\left(\sim 2000^{\circ} \mathrm{C}\right)$. Such hightemperature deposition process in turn invokes an intrinsic problem for the growth of complex oxides, e.g., a difficulty in controlling chemical composition because an element with higher vapor pressure evaporates much faster than the other elements during the deposition (Fig. 1 (upper)). In an extreme case that an element has an evaporation rate faster than the sticking rate of the deposition precursor, it is impossible to grow the complex oxides.

To overcome the difficulty in a conventional VPE, we have developed "Reactive Solid-Phase-Epitaxy (R-SPE)" as illustrated in Fig. 1(lower), ${ }^{1)}$ where a bilayer laminate composed of a thin epitaxial layer of simple oxide or metal grown on a substrate and a polycrystalline layer or powder source is thermally annealed at high-temperatures $\left(>1000^{\circ} \mathrm{C}\right)$. The solid-state chemical reaction at high-temperatures leads to the formation of the thin single-crystalline layer on the substrate, which may act as "an epitaxial template" for successive homoepitaxial growth of the film. High-quality epitaxial films of $\mathrm{InGaO}_{3}(\mathrm{ZnO})_{m}$ (where $m=$ integer $\left.)^{1)} \operatorname{In}_{2} \mathrm{O}_{3}(\mathrm{ZnO})_{\mathrm{m}}{ }^{6}{ }^{6}\right)$ $\mathrm{LaCuOCh}$ (where $\mathrm{Ch}=\mathrm{S}$ or Se), ${ }^{7)} \mathrm{ZnRh}_{2} \mathrm{O}_{4}{ }^{8)}$ and $\mathrm{Na}_{x} \mathrm{CoO}_{2}$ (where $x \sim 0.8)^{9)}$ with a layered structure were successfully fabricated using this technique, which would have been impossible by conventional VPE. Here I review high-quality epitaxial film growth of $\mathrm{InGaO}_{3}(\mathrm{ZnO})_{5}, \mathrm{LaCuOS}$ and $\mathrm{Na}_{0.8} \mathrm{CoO}_{2}$ by R-SPE.

2. Homologous series of $\operatorname{lnGaO}_{3}(\mathrm{ZnO})_{m}(m=\text { integer })^{1)}$ Homologous series of $L n M \mathrm{O}_{3}(\mathrm{ZnO})_{m}(\mathrm{Ln}=\mathrm{In}, \mathrm{Sc}$ or $\mathrm{Lu}$, $\mathrm{M}=\mathrm{Al}, \mathrm{Ga}, \mathrm{In}$, or $\mathrm{Fe}, m=$ integer $)^{10-17)}$ may exhibit the quantum effect due to its natural MQW structure. The crystal structure of $L_{n M O}(\mathrm{ZnO})_{m}(L n=\mathrm{In}, M=\mathrm{Ga}, m=5$, Fig. 2) consists of an alternative stack of $\mathrm{LnO}_{2}{ }^{-}$layers $\left(\mathrm{Ln}^{3+}\right.$ ion locates at an octahedral site formed by oxygen) and $\mathrm{MO}^{+}$ $(\mathrm{ZnO})_{m}$ blocks $\left(\mathrm{M}^{3+}\right.$ and $\mathrm{Zn}^{2+}$ ions take at trigonal-bipiramidal and tetrahedral coordination, respectively), making up the superlattice structure along the $[0001] . .^{15)-17)} \mathrm{A}$ unique feature of this material is that thickness of the $\mathrm{MO}^{+}(\mathrm{ZnO})_{m}$ block is varied by simply changing the chemical composition, while 

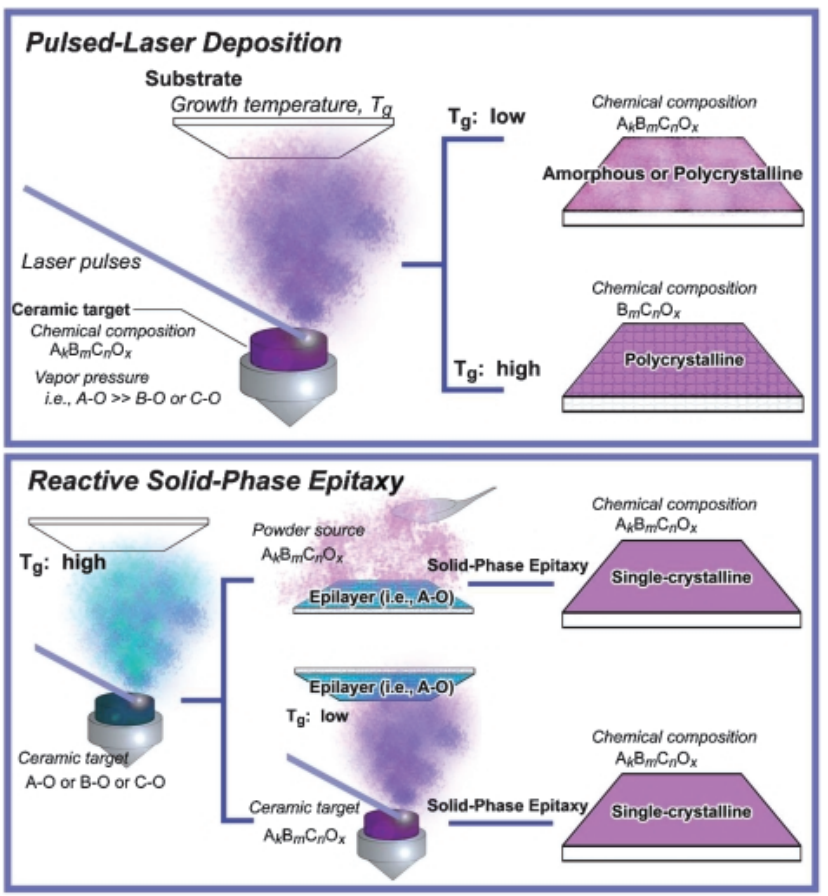

Fig. 1. (upper) Difficulty of conventional pulsed-laser deposition for layered complex oxide, $A_{k} B_{m} C_{n} O_{x}(A, B$ and $C$ : metallic atom, $k$, $m, n$ and $x$ : arbitrary integer). Amorphous or polycrystalline film of $A_{k} B_{m} C_{n} O_{x}$ is obtained by low-temperature deposition. An element with higher vapor pressure $(\mathrm{A}-\mathrm{O})$ evaporates much faster than the other elements ( $\mathrm{B}-\mathrm{O}$ and $\mathrm{C}-\mathrm{O}$ ) during high-temperature deposition. (lower) Basic concept of R-SPE method. A bilayer laminate composed of a thin epitaxial layer of simple oxide (A-O or B-O or C-O) or metal grown on a substrate and a polycrystalline layer or powder source of target $A_{k} B_{m} C_{n} O_{x}$ is thermally annealed at high-temperatures $\left(\sim 1000^{\circ} \mathrm{C}\right)$. The solid-state reaction at high-temperatures leads to the formation of the thin single-crystalline layer on the substrate, which may act as "an epitaxial template" for successive homoepitaxial SPE growth of the film.

that of the $\mathrm{LnO}_{2}{ }^{-}$layer is unchanged. This may give the control for electrical and optical properties related to the carrier confinement effects because thickness of the $\mathrm{MO}^{+}(\mathrm{ZnO})_{m}$ block corresponds to the quantum well width.

Although many studies have studied the electronic conductive ${ }^{18)-20)}$ and thermoelectric energy conversion characteristics ${ }^{21)}$ of $L n \mathrm{MO}_{3}(\mathrm{ZnO})_{m}(L n=\mathrm{In}, M=\mathrm{In}$ or $\mathrm{Ga})$, no noticeable features inherent to the layered structure have been identified yet due to absence of high-quality single-crystalline epitaxial film. We have engaged in intensive efforts to fabricate epitaxial $\mathrm{InGaO}_{3}(\mathrm{ZnO})_{m}$ films at high temperatures by conventional PLD method on (111)-face of yttria-stabilizedzirconia (YSZ) substrate. When substrate temperatures were increased up to $800^{\circ} \mathrm{C}$, the resulting polycrystalline films were composed of a mixture of $\mathrm{In}_{2} \mathrm{O}_{3}$ and $\mathrm{ZnGa}_{2} \mathrm{O}_{4}$, irrespective of varying several deposition parameters. Thus, we concluded that epitaxial film of $\mathrm{InGaO}_{3}(\mathrm{ZnO})_{m}$ is impossible to fabricate by simple PLD method.

Although single-crystalline film growth of $\mathrm{LnMO}_{3}(\mathrm{ZnO})_{m}$ is very difficult, bulk single crystals of $\mathrm{LuFeO}_{3}(\mathrm{ZnO})_{m}$ have been grown by means of the solid-state reaction of the mixture between $\mathrm{Lu}_{2} \mathrm{O}_{3}, \mathrm{Fe}_{2} \mathrm{O}_{3}$ and $\mathrm{ZnO}$ powders and successive grain growth in a platinum tube at $1550^{\circ} \mathrm{C} .{ }^{17)}$ This suggests that a small single-crystalline grain grows efficiently as a result of homoepitaxial growth from the solid-phase at high tempera- ture. This consideration leads to the expectation that singlecrystalline $L n M \mathrm{O}_{3}(\mathrm{ZnO})_{m}$ films can be grown from the solidphase if a thin single-crystalline layer is once formed just on the substrate.

Based on this idea, we have developed the R-SPE method. The R-SPE procedure (Fig. 3) for the growth of singlecrystalline $\mathrm{InGaO}_{3}(\mathrm{ZnO})_{5}$ films is as follows. Step 1: a $\mathrm{ZnO}$ epitaxial layer was grown on a (111)-YSZ substrate by PLD at $600^{\circ} \mathrm{C}^{22)}$ Thickness of the $\mathrm{ZnO}$ epitaxial layer was $\sim 2 \mathrm{~nm}$, evaluated by grazing incidence X-ray reflectivity (GIXR) measurements. Step 2: a 150-nm-thick polycrystalline $\mathrm{InGaO}_{3}$ $(\mathrm{ZnO})_{5}$ film was deposited on the $\mathrm{ZnO}$ epitaxial layer at room temperature $\left(25^{\circ} \mathrm{C}\right)$. X-ray photoelectron spectroscopy (XPS) revealed that the chemical composition of the deposited $\mathrm{InGaO}_{3}(\mathrm{ZnO})_{5}$ film differs insignificantly from that of the target. ${ }^{23)}$ Step 3: The resultant bilayer film was fully covered by placing a YSZ plate $\left(10 \mathrm{~mm} \times 10 \mathrm{~mm} \times 0.5 \mathrm{~mm}^{\mathrm{t}}\right)$ on the film surface to suppress vaporization of $\mathrm{ZnO}$ and $\operatorname{In}_{2} \mathrm{O}_{3}$ during the annealing in step 4. Step 4: The bilayer film was annealed at $1400^{\circ} \mathrm{C}$ for $0.5 \mathrm{~h}$ in air. Step 5: The film was cooled down to room temperature in the furnace. Finally, a YSZ cap plate was removed and the surface of the annealed film looks very clean without chemical reaction with the YSZ plate.

Figure 4 (b) shows a cross-sectional high-resolution transmission electron microscopy (HRTEM, JEM-4010, acceleration voltage: $400 \mathrm{kV}$, JEOL Co.) image of the $\mathrm{InGaO}_{3}(\mathrm{ZnO})_{5}$ film grown by the R-SPE method. A periodic stripe pattern with an interval of $1.9 \mathrm{~nm}$, which corresponds to $d_{0003}$ in $\mathrm{InGaO}_{3}(\mathrm{ZnO})_{5}$, is seen in an atomic-scale resolution (Fig. 4 (a)), which directly shows the superlattice structure of the $\mathrm{InGaO}_{3}(\mathrm{ZnO})_{5}$ film epitaxially grown on the (111)-YSZ surface. Atomically flat terraces and steps are observed in topographic atomic force microscope (AFM, SPI-3800N, S.I.I.) image of the $\mathrm{InGaO}_{3}(\mathrm{ZnO})_{5}$ film (Fig. $4(\mathrm{c})$ ). The step height is $1.9 \mathrm{~nm}$, corresponding to the space between the adjacent $\mathrm{InO}_{2}{ }^{-}$layers. These results clearly demonstrate that singlecrystalline films of homologous series $\mathrm{InGaO}_{3}(\mathrm{ZnO})_{m}$ are successfully grown on YSZ substrates by the R-SPE method.

To clarify the growth mechanism in the R-SPE method, we have investigated the change in the crystallographic orientation of the bilayer films grown on the (111)-YSZ substrate during thermal annealing using HRTEM. ${ }^{24)}$ Figure 5 shows the HRTEM images of the bilayer film after annealing at various temperatures. Amorphous $\mathrm{InGaO}_{3}(\mathrm{ZnO})_{5}$ film slightly containing crystallized small grain are observed on the $\mathrm{ZnO}$ layer (2-nm-thick) in the as-prepared film (Fig. 5(a)). The distribution of the tilt angle of $0002 \mathrm{ZnO}$ was $\sim 0.03$ degrees evaluated by high-resolution X-ray diffraction (HR-XRD, ATX-G, Rigaku Co.). After annealing at $800^{\circ} \mathrm{C}$ (Fig. 5(b)), randomly oriented polycrystalline grains of $\operatorname{InGaO}_{3}(\mathrm{ZnO})_{5}$, whose sizes become much larger compared to those in the asdeposited film, are observed on the $\mathrm{ZnO}$ epitaxial layer. The distribution of the tilt angle of $0002 \mathrm{ZnO}$ is unchanged $(\sim 0.03$ degrees) by the annealing at $800^{\circ} \mathrm{C}$. These observations suggest that the crystallization and the grain growth of $\mathrm{InGaO}_{3}$ $(\mathrm{ZnO})_{5}$ starts to occur below $800^{\circ} \mathrm{C}$, without reacting the polycrystalline $\mathrm{InGaO}_{3}(\mathrm{ZnO})_{5}$ with the $\mathrm{ZnO}$ epitaxial layer. When the film is annealed at $1000^{\circ} \mathrm{C}$ the $\mathrm{ZnO}$ epitaxial is no longer detected and a $\sim 50$-nm-thick single-crystalline $\mathrm{InGaO}_{3}$ $(\mathrm{ZnO})_{5}$ layer is formed just on the substrate (Fig. 5(c)). It implies that the solid-state reaction between the polycrystalline $\mathrm{InGaO}_{3}(\mathrm{ZnO})_{5}$ and the $\mathrm{ZnO}$ epitaxial layer occurs at temperatures higher than $1000^{\circ} \mathrm{C}$, leading to the formation of the epitaxial layer. At this temperature, the tilt angle of 0001 $\mathrm{InGaO}_{3}(\mathrm{ZnO})_{5}$ exhibits a rather large distribution of $\sim 0.5$ 


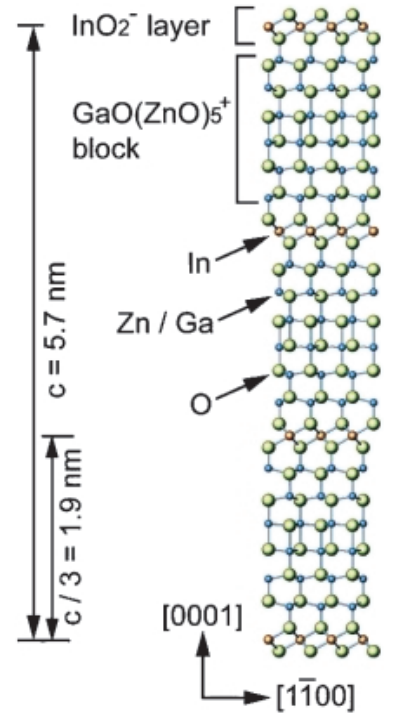

Fig. 2
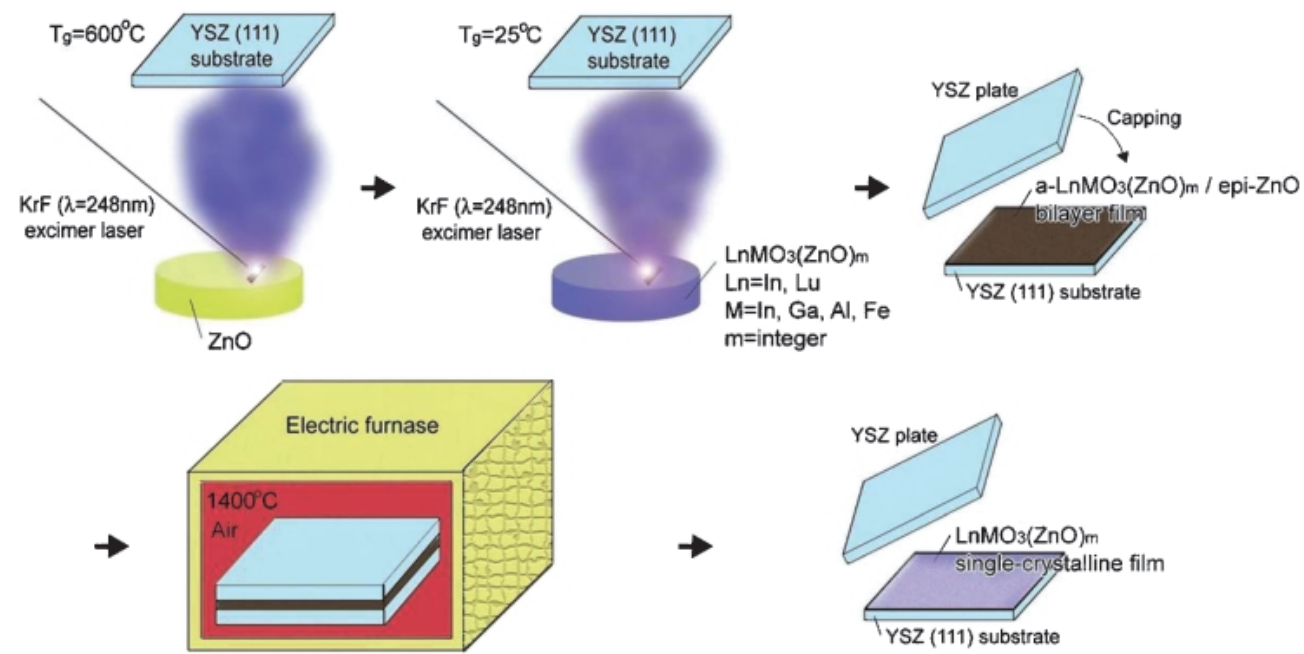

Fig. 3

Fig. 2. Schematic crystal structure of $\mathrm{InGaO}_{3}(\mathrm{ZnO})_{m}(m=5)$. Crystal symmetry: hexagonal $(m=$ even $)$ or rhombohedral $(m=$ odd $)$, space group: $P 6_{3} m m c(m=$ even $)$ or R-3m $(m=$ odd $)$.

Fig. 3. Fabrication procedure for single-crystalline films of $L n M \mathrm{O}_{3}(\mathrm{ZnO})_{m}(L n=\mathrm{Lu}$ or In, $M=\mathrm{Al}, \mathrm{Ga}$, In or Fe, $m=$ integer $)$ by the R-SPE method. Step 1: Extremely thin ( 2-nm-thick) ZnO epitaxial layer is grown on a YSZ substrate by PLD at $600^{\circ} \mathrm{C}$. Step 2: a 150 -nm-thick amorphous $\mathrm{LnMO}_{3}(\mathrm{ZnO})_{m}$ film is deposited on the $\mathrm{ZnO}$ epitaxial layer at room temperature $\left(25^{\circ} \mathrm{C}\right)$. Step 3: The resultant bilayer film is fully covered by placing a YSZ plate $\left(10 \mathrm{~mm} \times 10 \mathrm{~mm} \times 0.5 \mathrm{~mm}^{\mathrm{t}}\right)$ on the film surface. Step 4: The bilayer film is annealed at $1400^{\circ} \mathrm{C}$ for $0.5 \mathrm{~h}$ in air.

(a)
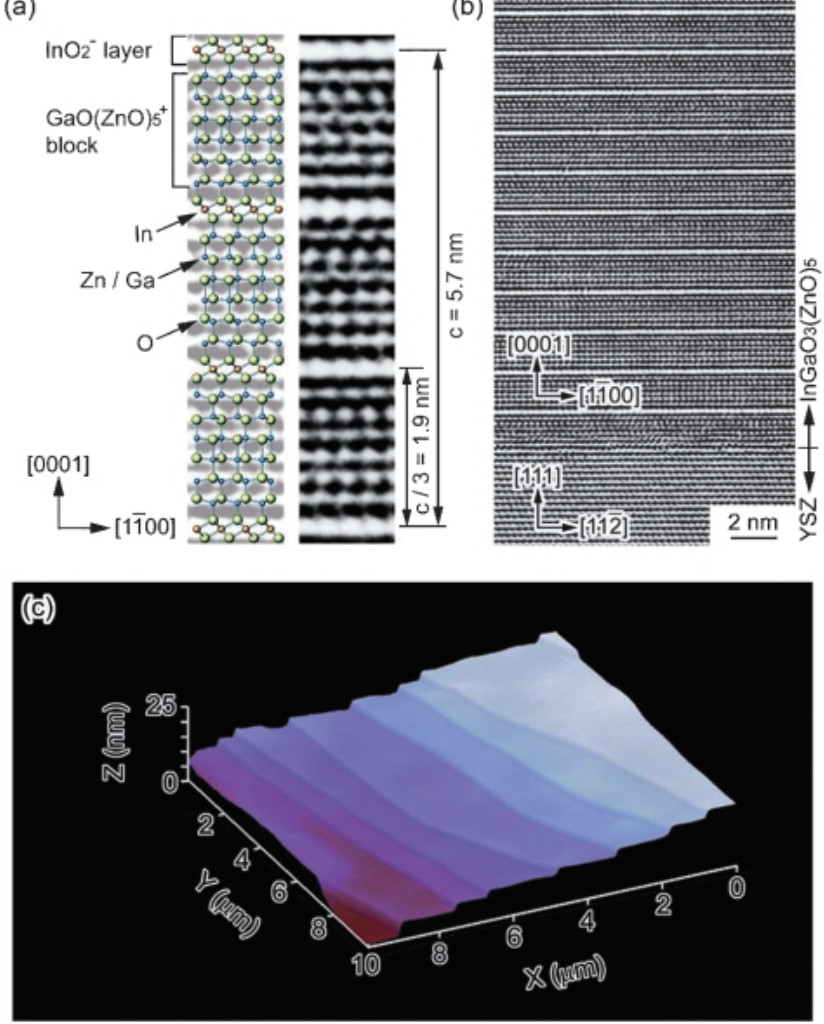

Fig. 4. (a) (b) Cross-sectional HRTEM lattice image of the R-SPE grown $\mathrm{InGaO}_{3}(\mathrm{ZnO})_{5}$ single-crystalline film. Schematic crystal structure is also shown for comparison. (c) Topographic AFM image of the $\mathrm{InGaO}_{3}(\mathrm{ZnO})_{5}$ film. Atomically flat terraces and steps are observed. The step height is $1.9 \mathrm{~nm}$, corresponding to the space between the adjacent $\mathrm{InO}_{2}{ }^{-}$layers. degrees, because randomly oriented $\mathrm{InGaO}_{3}(\mathrm{ZnO})_{5}$ grains still remain in the area above the growth front of the epitaxial $\mathrm{InGaO}_{3}(\mathrm{ZnO})_{5}$ layer. Finally, an almost perfect superlattice structure of $\mathrm{InGaO}_{3}(\mathrm{ZnO})_{5}$ is formed over the entire area of the film after the annealing at $1400^{\circ} \mathrm{C}$ (Fig. $5(\mathrm{~d})$ ). The distribution of $0001 \mathrm{InGaO}_{3}(\mathrm{ZnO})_{5}$ tilt angle was significantly reduced to less than 0.1 degrees, which is consistent with the result of the HRTEM observation. From these observations, the R-SPE process is summarized as follows: First, a thin single-crystalline layer of $\mathrm{InGaO}_{3}(\mathrm{ZnO})_{m}$ is formed epitaxially on the substrate by the solid-state chemical reaction at $\sim 1000^{\circ} \mathrm{C}$. Then, homoepitaxial growth of $\mathrm{InGaO}_{3}(\mathrm{ZnO})_{m}$ film takes place at $1400^{\circ} \mathrm{C}$ on the first layer via the solid-phase to form the single-crystalline film.

Recently we have clarified the intrinsic carrier transport for $\mathrm{InGaO}_{3}(\mathrm{ZnO})_{5}$ using single-crystalline film grown by $\mathrm{R}-\mathrm{SPE}^{25)}$ and successfully fabricated high-performance transparent field-effect transistors. ${ }^{26)}$ The device exhibited excellent performance such as an on-to-off current ratio of $\sim 10^{6}$ and a field-effect mobility of $\sim 80 \mathrm{~cm}^{2} \mathrm{~V}^{-1} \mathrm{~s}^{-1}$ and normally-off characteristics with operation insensitive to visible light irradiation. The result provides a step toward the realization of transparent electronics for next-generation optoelectronics. ${ }^{27)}$

3. Layered oxychalcogenide, $\mathrm{LaCuOCh}(\mathrm{Ch}=\mathrm{S} \text { and } \mathrm{Se})^{7)}$ We recently found $\mathrm{LaCuOCh}(C h=\mathrm{S}$ or $\mathrm{Se})$ is a novel transparent $p$-type semiconductor, which has been explored by an extension of our chemical design concept for $p$-type semiconducting oxides ${ }^{28)-32)}$ to the oxychalcogenide system. ${ }^{33)}$ $\mathrm{LaCuOCh}$ has a layered natural MQW structure, composed of $\left(\mathrm{La}_{2} \mathrm{O}_{2}\right)^{2+}$ and $\left(\mathrm{Cu}_{2} \mathrm{Ch}_{2}\right)^{2-}$ layers alternatively stacked along the $c$-axis $\left(\right.$ Fig. 6) ${ }^{34), 35)}$ The covalent $\left(\mathrm{Cu}_{2} \mathrm{Ch}_{2}\right)^{2-}$ layers, in which $\mathrm{Cu}$ is tetrahedrally coordinated by four $\mathrm{Ch}^{2-}$ ions, dominantly contribute to the top of the valence band, working as conduction paths for hole carriers (well) ${ }^{36)}$ On the other hand, the ionic $\left(\mathrm{La}_{2} \mathrm{O}_{2}\right)^{2+}$ layers acting as a barrier layer to 

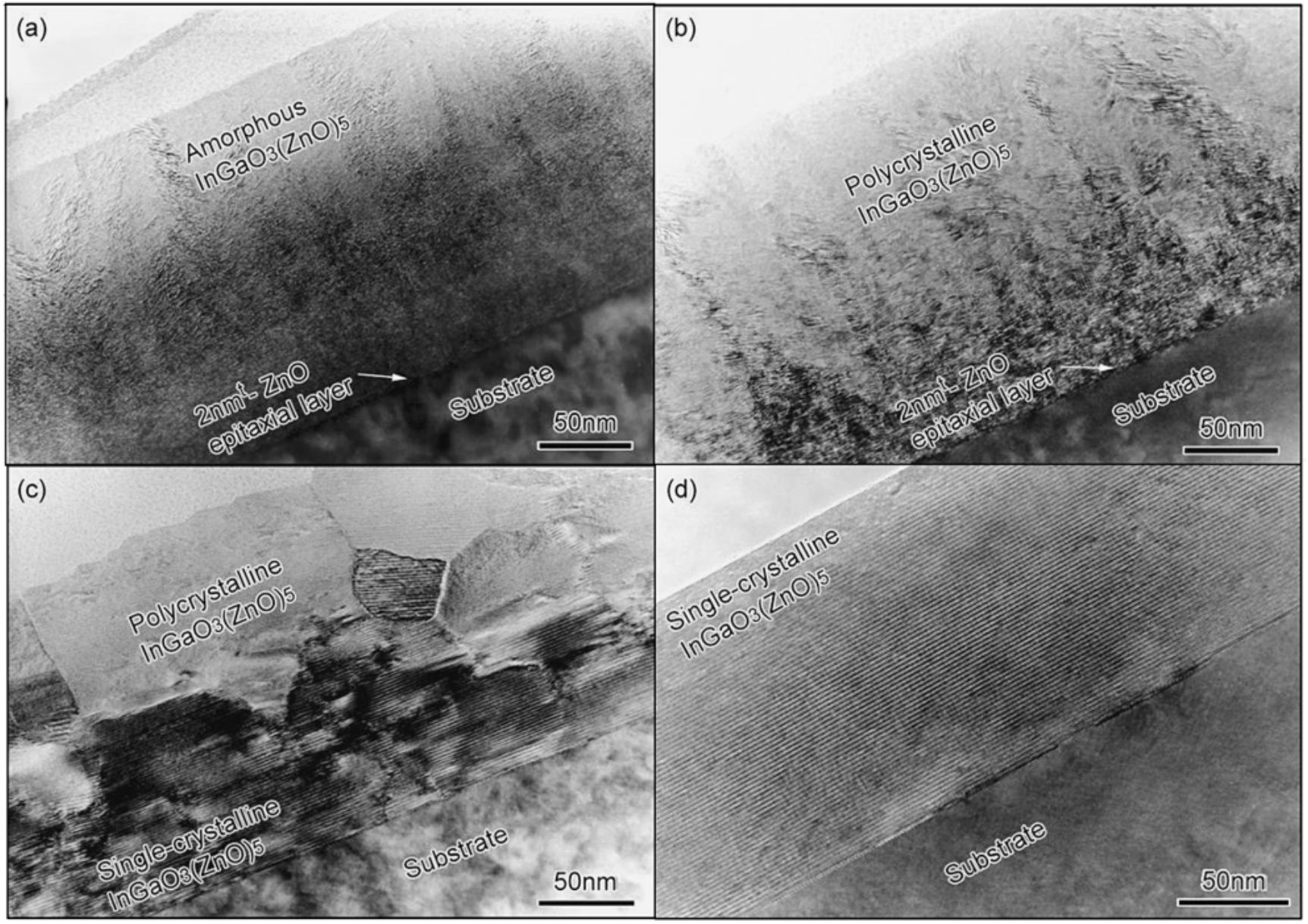

Fig. 5. Cross-sectional HRTEM images of the amorphous $\mathrm{InGaO}_{3}(\mathrm{ZnO})_{5} /$ epi- $\mathrm{ZnO}$ bilayer after annealing at different temperatures $((\mathrm{a})$ without heating, (b) after heated at $800^{\circ} \mathrm{C}$, (c) after heated at $1000^{\circ} \mathrm{C}$, and (d) after heated at $1400^{\circ} \mathrm{C}$ ).

confine positive holes in the two-dimensional $\left(\mathrm{Cu}_{2} \mathrm{Ch}_{2}\right)^{2-}$ layers and preserve transparency in the visible range. The electrical conductivity of the material is controllable by doping of divalent ions $\mathrm{Mg}^{2+}$, which act as acceptors by substituting $\mathrm{La}^{3+}$ ions. ${ }^{37)}$ Sharp near-UV photoluminescence peak associated with exciton is observed around the fundamental absorption edge even at room temperature. $\left.{ }^{38)}-40\right)$ Further, we successfully controlled the bandgap of the oxychalcogenide by the formation of a complete alloy between LaCuOS and LaCuOSe. ${ }^{41)}$ The bandgap of $\mathrm{LaCuOS}_{1-x} \mathrm{Se}_{x}$ systematically varies from $3.1 \mathrm{eV}$ to $2.8 \mathrm{eV}$ with an increase in $x$ from $x=0.0$ to 1.0 . Therefore, epitaxial film growth is of critical importance for the fabrication of $\mathrm{LaCuOCh}$-based optoelectronic devices such as near UV-LEDs and LDs.

We have engaged in intensive efforts to grow epitaxial LaCuOS films at high temperatures by conventional PLD method on YSZ or MgO substrates. Films deposited at temperatures below $\sim 500^{\circ} \mathrm{C}$ in $\mathrm{H}_{2} \mathrm{~S}$ atmosphere were always amorphous, and no crystallization occurred below $\sim 500^{\circ} \mathrm{C}$. When substrate temperatures were increased up to $800^{\circ} \mathrm{C}$, the resulting polycrystalline films were composed of a mixture of $\mathrm{LaCuOS}, \mathrm{La}_{2} \mathrm{O}_{3}$ and $\mathrm{La}_{2} \mathrm{O}_{2} \mathrm{~S}$, irrespective of varying several deposition parameters.

In order to fabricate epitaxial films of $\mathrm{LaCuOCh}$, we applied R-SPE method (Fig. 7).$^{7)}$ 5-nm-thick $\mathrm{Cu}$ layer was deposited at $400^{\circ} \mathrm{C}$ under a vacuum $\left(\sim 10^{-5} \mathrm{~Pa}\right)$, and amorphous $\mathrm{LaCuOS}$ (a-LaCuOS, hereafter) layer was deposited at $25^{\circ} \mathrm{C}$ in a $\mathrm{H}_{2} \mathrm{~S}$ atmosphere $\left(\mathrm{H}_{2} \mathrm{~S} / \mathrm{Ar}=25 \%, 0.5 \mathrm{~Pa}\right)$. Then, the bilayer films were covered with YSZ plates and annealed at $1000^{\circ} \mathrm{C}$. All the thermal-annealing treatments were performed in evacuated $\mathrm{SiO}_{2}$ glass tubes with a small amount of $\mathrm{LaCuOS}$ powder. The YSZ plate and the LaCuOS powders are crucial for maintaining the stoichiometric composition of the films during annealing.

Figure 8 (a) shows a cross-sectional HRTEM image of the LaCuOS film on a YSZ substrate by the R-SPE method. Layered patterns due to $(00 l)$ planes of LaCuOS are stacked parallel to the substrate surface over the whole area of the film. Square shaped domains with atomically flat terraces and steps are observed in the topographic AFM image of the LaCuOS film (Fig. 8(b)). These results clearly demonstrate that the resultant LaCuOS film was high-quality epitaxial film.

In order to clarify the growth mechanism in the R-SPE method, we have investigated the change in the crystallographic orientation of the bilayer films grown on the (001)-YSZ substrate during thermal annealing using HRTEM. ${ }^{42)}$ Figure 9 shows cross-sectional HRTEM images of a-LaCuOS $/ \mathrm{Cu} /$ (001)-YSZ samples as-deposited (a) and annealed at $500^{\circ} \mathrm{C}$ (b), $800^{\circ} \mathrm{C}(\mathrm{c})$, and $1000^{\circ} \mathrm{C}$ (d). Island structures are formed at the a-LaCuOS-YSZ substrate interface in the as-deposited sample (Fig. 9(a)). When annealed at $500^{\circ} \mathrm{C}$ (Fig. 9(b)), thin $(\sim 10 \mathrm{~nm})$ crystallites, exhibiting a layered structure, are observed at the interface. The number density of this crystal- 


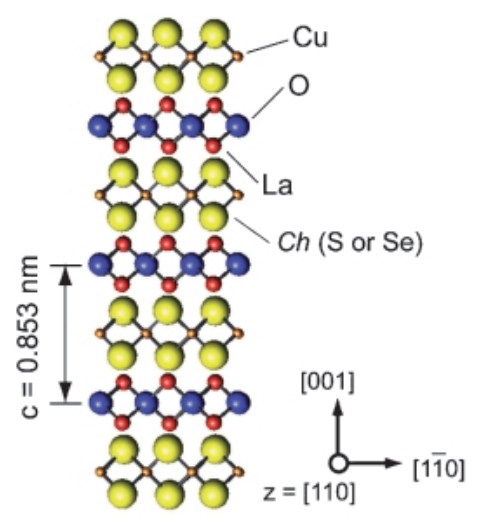

Fig. 6

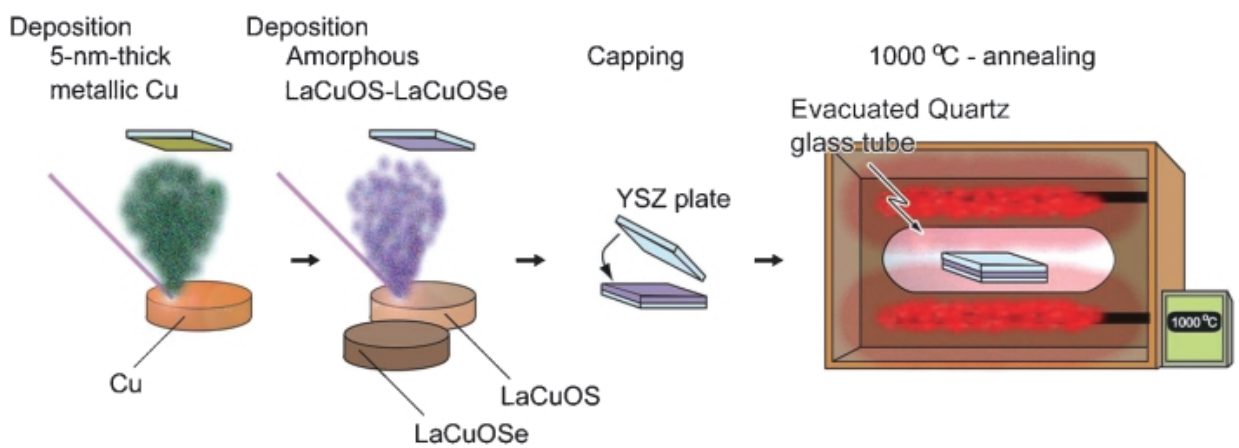

Fig. 7

Fig. 6. Schematic crystal structure of $\mathrm{LaCuOCh}(\mathrm{Ch}=\mathrm{S}$ or Se). Crystal symmetry: tetragonal, space group: $P 4 / \mathrm{nmm}$. Each layer is constituted by edge-shared $\mathrm{La}_{4} \mathrm{O}$ and $\mathrm{CuCh}_{4}$ tetrahedra. The $c$-axis length of $\mathrm{LaCuOS}$ is $0.853 \mathrm{~nm}$.

Fig. 7. Fabrication procedure for epitaxial films of $\mathrm{LaCuOCh}(\mathrm{Ch}=\mathrm{S}$ or Se $)$ by the R-SPE method. Step 1: 5-nm-thick Cu metal is deposited by PLD at $500^{\circ} \mathrm{C}$ on a substrate. Step 2: amorphous LaCuOS or LaCuOSe layer was deposited on the Cu layer using a sintered LaCuOS or LaCuOSe target at room temperature. Step 3: The resultant bilayer film is fully covered by placing a YSZ plate $\left(10 \mathrm{~mm} \times 10 \mathrm{~mm} \times 0.5 \mathrm{~mm}^{\mathrm{t}}\right)$ on the film surface. Step 4: The bilayer film is annealed at $1000^{\circ} \mathrm{C}$ in an evacuated $\mathrm{SiO}_{2}$ glass tube.

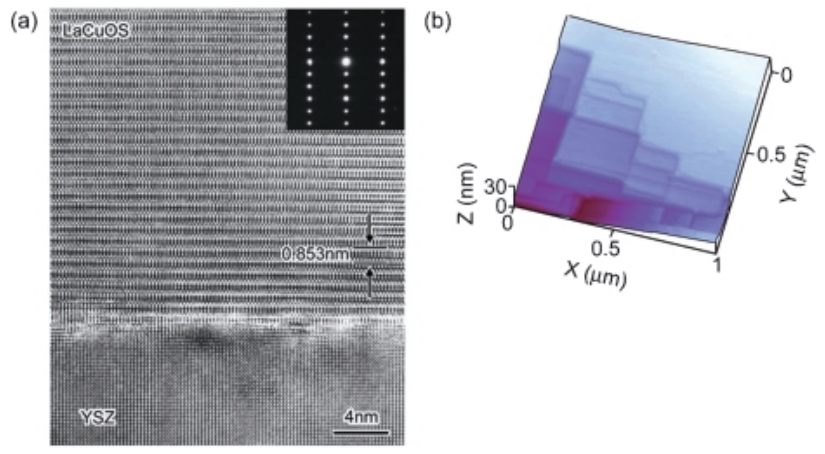

Fig. 8. (a) Cross-sectional HRTEM image of the R-SPE grown LaCuOS on (001)-face of YSZ substrate. (b) Topographic AFM image of the LaCuOS epitaxial film. Square shaped domains with atomically flat terraces and steps are observed.

lite is similar to that of the $\mathrm{Cu}$ island observed in Fig. 9(a), suggesting that the $\mathrm{Cu}$ island is converted to the crystallite without coagulating. Figure 9 (c) shows that the crystallite serves as a seed for growing large grained epitaxial layers at temperatures $\geq 500^{\circ} \mathrm{C}$. However, nonoriented polycrystalline $\mathrm{LaCuOS}$ grains are still seen in the film surface region. Finally at $1000^{\circ} \mathrm{C}$, a $\mathrm{LaCuOS}$ epitaxial crystal grows in the entire area, as seen in Fig. 9(d). From these observations, the R-SPE process is summarized as follows: The thin metallic $\mathrm{Cu}$ layer deposited between a-LaCuOS and YSZ (Fig. 9(a)) works as an initiator to form epitaxial $\mathrm{LaCuOS}$ seeds at temperatures $\geq 500^{\circ} \mathrm{C}$. Single-crystalline grain growth proceeds from the epitaxial $\mathrm{LaCuOS}$ seeds toward the top of film surface at $800^{\circ} \mathrm{C}$ to $1000^{\circ} \mathrm{C}$.

Very recently we have successfully demonstrated the room temperature operation of blue light emitting diode (blue LED) using a $p-n$ heterojunction composed of a wide bandgap $p$-type oxychalcogenide LaCuOSe epitaxial film, and an $n$-type amorphous $\mathrm{In}-\mathrm{Ga}-\mathrm{Zn}-\mathrm{O}(\mathrm{In} / \mathrm{Ga} / \mathrm{Zn}$ atomic ratio $\sim 1 / 1 / 5) .{ }^{43)}$ A blue electroluminescence (EL) peaking at $\lambda$ $\sim 430 \mathrm{~nm}$ and associated with the intrinsic exciton of $\mathrm{LaCuOSe}$, is observed at room temperature by applying a forward bias voltage above $\sim 8 \mathrm{~V}$. The successful operation of the LED device at room temperature indicates that layered oxychalcogenides $\mathrm{LnCuOCh}$ ( $\mathrm{L} n=$ lanthanide, $C h=$ chalcogen) have a substantial potential as the light-emitting layer in optoelectronics devices that operate in the blue-ultraviolet region.

4. Layered Sodium Cobaltite, $\mathrm{Na}_{x} \mathrm{CoO}_{2}(x \sim 0.8)^{9)}$

Recently, sodium cobalt-oxide, $\mathrm{Na}_{x} \mathrm{CoO}_{2} \quad(x=0.5-0.9$, hexagonal lattice, space group: $P 6_{3} / m m c, a=0.284 \mathrm{~nm}, c=$ $1.081 \mathrm{~nm}^{44)}$ ) (Fig. 10) has attracted emerging attention toward the realization of oxide-based thermoelectric energy conversion (TE) devices, such as a thermoelectric generator and Peltier cooler, because they have potential advantages over conventional TE devices, such as $\mathrm{Bi}_{2} \mathrm{Te}_{3}$-based TE devices, with respect to thermal stability and environmental compatibility. ${ }^{45)-49)}$ This material also attracts much attention because it can be converted into a superconductor (transition temperature, $T_{\mathrm{c}}=4.7 \mathrm{~K}$ ) by introducing $\mathrm{H}_{2} \mathrm{O}$ molecules into a layer between the two adjacent $\mathrm{CoO}_{2}{ }^{-}$layers. ${ }^{50), 51)}$ Although a number of TE properties for bulk single crystal $^{45), 46)}$ and sintered polycrystalline $\mathrm{Na}_{x} \mathrm{CoO}_{2}{ }^{47)-49)}$ have been reported to date, those of thin films have not been reported so far. Highquality epitaxial film of $\mathrm{Na}_{x} \mathrm{CoO}_{2}$ is obviously preferable for high-performance thin film TE devices, primarily because epitaxial films exhibit intrinsic electrical properties as bulk single crystal.

We applied R-SPE technique to the growth of $\mathrm{Na}_{x} \mathrm{CoO}_{2}$ epitaxial film. Figure 11 schematically illustrates the R-SPE procedure for the growth of epitaxial $\mathrm{Na}_{x} \mathrm{CoO}_{2}$ films. ${ }^{9}{ }^{9}$ Step 1: High-quality epitaxial film of (111)-oriented $\mathrm{CoO}$ was deposited on a (0001) -face of $\alpha-\mathrm{Al}_{2} \mathrm{O}_{3}$ substrate $(10 \mathrm{~mm} \times 10$ $\mathrm{mm} \times 0.5 \mathrm{~mm}^{\mathrm{t}}$ ) at $700^{\circ} \mathrm{C}$ by PLD using a $\mathrm{Co}_{3} \mathrm{O}_{4}$ sintered disk as a target. Step 2: surface of the PLD-deposited $\mathrm{CoO}$ film was fully capped by YSZ single-crystalline plate $(10 \mathrm{~mm} \times 10$ $\left.\mathrm{mm} \times 0.5 \mathrm{~mm}^{\mathrm{t}}\right)$ to keep the surface clean. Step 3: $\mathrm{NaHCO}_{3}$ powder was put on the YSZ plate. Step 4: The sandwich specimen was annealed at $700^{\circ} \mathrm{C}$ for $1 \mathrm{~h}$ in air.

Figure 12 shows out-of-plane (a) and in-plane (b) X-ray Bragg diffraction patterns of the $\mathrm{Na}_{x} \mathrm{CoO}_{2}$ film grown on (0001) -face of $\alpha-\mathrm{Al}_{2} \mathrm{O}_{3}$ substrate by the R-SPE method. Only intense Bragg diffraction peaks of $0001 \mathrm{Na}_{x} \mathrm{CoO}_{2}$ are observed 


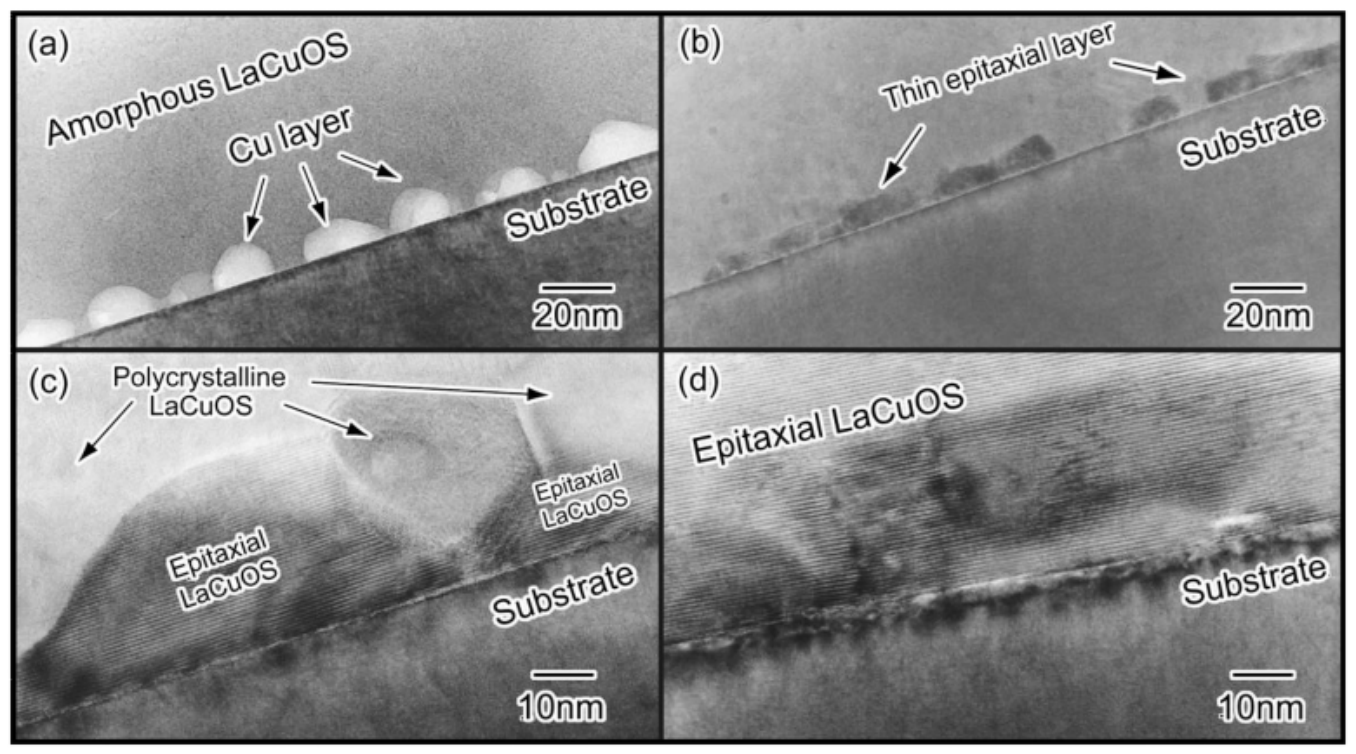

Fig. 9. Cross-sectional HRTEM images of annealed a-LaCuOS/Cu/(001)-YSZ at various temperatures. (a) As-deposited (nonannealed), (b) $500^{\circ} \mathrm{C}$, (c) $800^{\circ} \mathrm{C}$, and (d) $1000^{\circ} \mathrm{C}$. The incident direction of the electron beam is [010] of YSZ substrate.

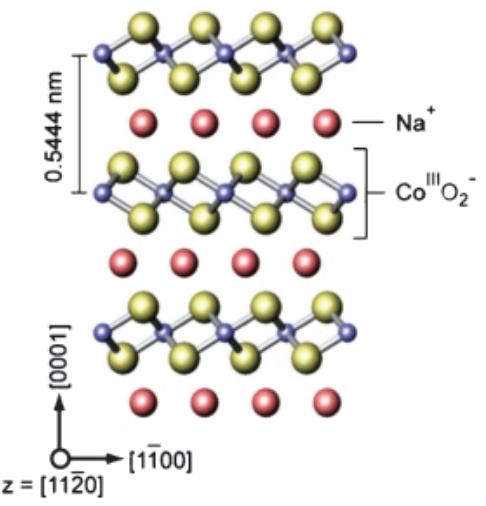

Fig. 10

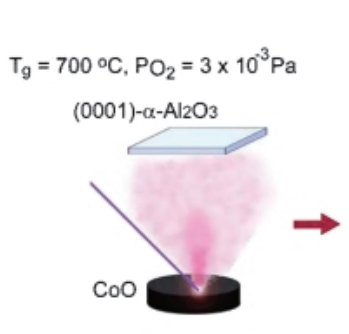

Step 1

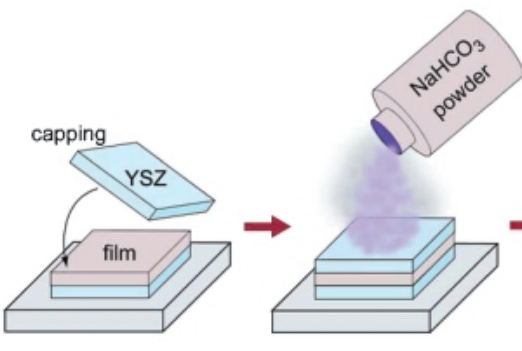

Step 3

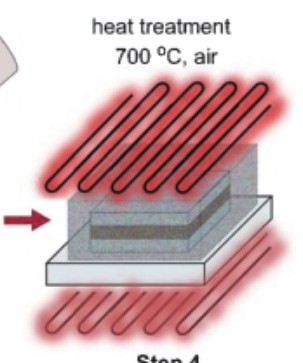

Step 4

Fig. 11

Fig. 10. Schematic crystal structure of $\mathrm{Na}_{x} \mathrm{CoO}_{2}(x \sim 0.8)$. Crystal symmetry: hexagonal, space group: $P 6_{3} m m c$.

Fig. 11. Fabrication procedure for epitaxial films of $\mathrm{Na}_{\mathrm{x}} \mathrm{CoO}_{2}(x \sim 0.8)$ by the R-SPE method. Step 1: Pulsed-laser-deposition of highly (111)oriented epitaxial film of $\mathrm{CoO}$ on a (0001)-oriented $\alpha-\mathrm{Al}_{2} \mathrm{O}_{3}$ substrate. Step 2: Surface capping by YSZ single-crystalline plate to keep the film surface clean. Step 3: Putting $\mathrm{NaHCO}_{3}$ powder on the YSZ plate. Step 4: Thermal annealing at $700^{\circ} \mathrm{C}$ in air.

together with $0006 \alpha-\mathrm{Al}_{2} \mathrm{O}_{3}$ (Fig. $12(\mathrm{a})$ ), indicating that the film was highly $c$-axis oriented. On the other hand, only intense Bragg peak of $11-20 \mathrm{Na}_{x} \mathrm{CoO}_{2}$ is seen together with 3-300 $\alpha-\mathrm{Al}_{2} \mathrm{O}_{3}$ (Fig. 12(b)), indicating that heteroepitaxial growth occurred with the following epitaxial relationship: (0001) $[11-20] \mathrm{Na}_{x} \mathrm{CoO}_{2} \|(0001)[1-100] \alpha-\mathrm{Al}_{2} \mathrm{O}_{3}$. Intense streak RHEED pattern of the film (inset) also support this conclusion. Topographic AFM image of the $\mathrm{Na}_{x} \mathrm{CoO}_{2}$ epitaxial film is shown in Fig. 12(c). A step-like structure composed of several flake-like domains is seen. The step increment was approximately $3 \mathrm{~nm}$, which is three times as long as that of the $c$-axis length of $\mathrm{Na}_{x} \mathrm{CoO}_{2}$, suggesting that step bunching occurred during the annealing at $700^{\circ} \mathrm{C}$. The chemical composition of the resultant film was evaluated to be $\mathrm{Na}_{0.83} \mathrm{CoO}_{2}$ by $\mathrm{X}$-ray fluorescence (XRF) measurement. Electrical conductivity $(\sigma)$, carrier concentration $(n)$, Hall mobility $(\mu)$, and Seebeck coefficient $(S)$, and power factor $\left(S^{2} \sigma\right)$ of the $\mathrm{Na}_{0.83}$ $\mathrm{CoO}_{2}$ epitaxial film were $1160 \mathrm{~S} \mathrm{~cm}^{-1}, 3.8 \times 10^{21} \mathrm{~cm}^{-3}, 1.9$ $\mathrm{cm}^{2} \mathrm{~V}^{-1} \mathrm{~s}^{-1},+117 \mu \mu \mathrm{VK}^{-1}$, and $1.6 \times 10^{-3} \mathrm{Wm}^{-1} \mathrm{~K}^{-2}$, respectively, which are comparable to those of bulk singlecrystalline $\mathrm{Na}_{x} \mathrm{CoO}_{2}$. These results suggest that the $\mathrm{Na}_{0.83} \mathrm{CoO}_{2}$ film grown by the R-SPE was high-quality epitaxial film.

We then investigated the change in the crystalline phase of the $\mathrm{CoO}$ epitaxial film grown on the $(0001)-\alpha-\mathrm{Al}_{2} \mathrm{O}_{3}$ substrate during the thermal annealing using HR-XRD to clarify the growth mechanism. Figure 13 (left) shows the out-of-plane XRD patterns of the $\mathrm{CoO}$ film after annealing at various temperatures. Only intense Bragg diffraction peak of $111 \mathrm{CoO}$ is seen together with $0006 \alpha-\mathrm{Al}_{2} \mathrm{O}_{3}$ at $25^{\circ} \mathrm{C}$. After annealing at $300^{\circ} \mathrm{C}, 111 \mathrm{Co}_{3} \mathrm{O}_{4}$ and $222 \mathrm{Co}_{3} \mathrm{O}_{4}$ peaks are additionally seen. After annealing at $500^{\circ} \mathrm{C}$, intensity of $111 \mathrm{Co}_{3} \mathrm{O}_{4}$ and 222 $\mathrm{Co}_{3} \mathrm{O}_{4}$ peaks are increased, while $111 \mathrm{CoO}$ peak intensity is decreased. The color of the film turned transparent (almost colorless) to brown. After annealing at $600^{\circ} \mathrm{C}$, the periphery of the film turned black $\left(\mathrm{Na}_{x} \mathrm{CoO}_{2}\right)$, while the center still remained transparent brown $\left(\mathrm{Co}_{3} \mathrm{O}_{4}\right)$. Finally, after the sam- 


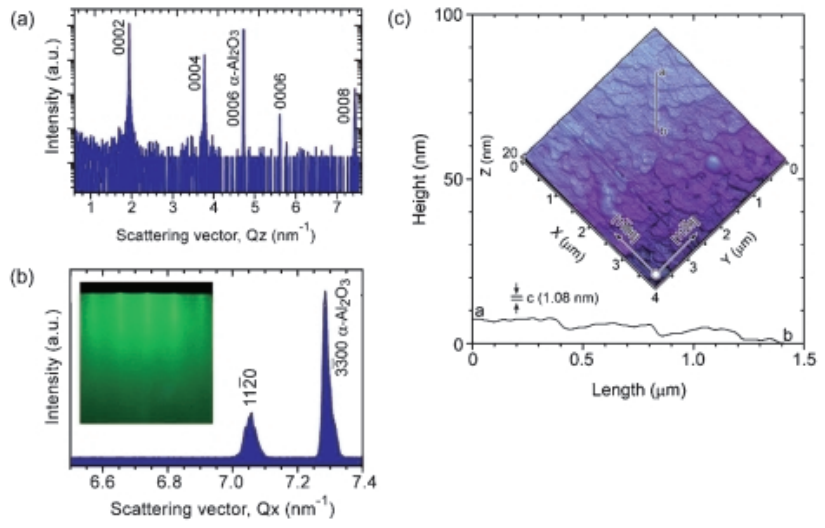

Fig. 12. (a) Out-of-plane and (b) in-plane X-ray Bragg diffraction patterns of the R-SPE grown $\mathrm{Na}_{\mathrm{x}} \mathrm{CoO}_{2}$ film. RHEED pattern of the $\mathrm{Na}_{\mathrm{x}} \mathrm{CoO}_{2}$ film is also shown in (b). (c) Topographic AFM image of the $\mathrm{Na}_{\mathrm{x}} \mathrm{CoO}_{2}$ epitaxial layer grown by the R-SPE method. Cross-sectional profile from $\mathbf{a}$ to $\mathbf{b}$ is also shown. Step-like structure composed of several flake-like domains is seen.

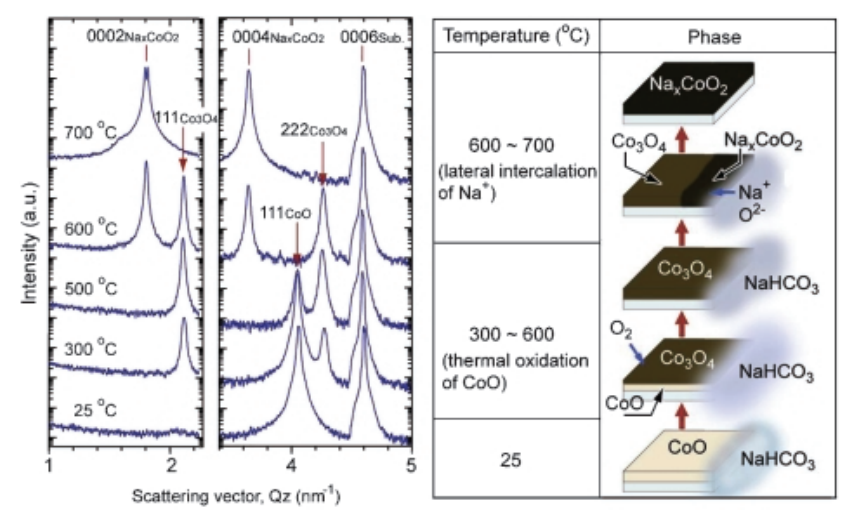

Fig. 13. (Left) Out-of-plane XRD pattern of $\mathrm{CoO}$ epitaxial layer after annealing with $\mathrm{NaHCO}_{3}$ powders at different temperatures (without heating, after heated at $300^{\circ} \mathrm{C}$, at $500^{\circ} \mathrm{C}$, at $600^{\circ} \mathrm{C}$, and at $700^{\circ} \mathrm{C}$ ). (Right) Schematic illustration of growth mechanism of $\mathrm{Na}_{x} \mathrm{CoO}_{2}$ epitaxial layer by the R-SPE method. Thermal oxidation of the $\mathrm{CoO}$ film into $\mathrm{Co}_{3} \mathrm{O}_{4}$ occurred at lower temperature (300$\left.500^{\circ} \mathrm{C}\right) . \mathrm{Na}_{\mathrm{x}} \mathrm{CoO}_{2}$ epitaxial layer is formed at $600-700^{\circ} \mathrm{C}$ via lateral diffusion of $\mathrm{Na}^{+}$ion into $\mathrm{Co}_{3} \mathrm{O}_{4}$ layers.

ple was annealed at $700^{\circ} \mathrm{C}$, only intense diffraction peaks of $\mathrm{Na}_{x} \mathrm{CoO}_{2}$ are seen together with $0006 \alpha-\mathrm{Al}_{2} \mathrm{O}_{3}$. The growth mechanism for the $\mathrm{Na}_{x} \mathrm{CoO}_{2}$ by the R-SPE method is schematically illustrated in Fig. 13 (right). First, thermal oxidation of $\mathrm{CoO}$ into $\mathrm{Co}_{3} \mathrm{O}_{4}$ occurs at lower temperature $\left(300-500^{\circ} \mathrm{C}\right)$. Then, the $\mathrm{Na}_{x} \mathrm{CoO}_{2}$ epitaxial layer is formed at $600-700^{\circ} \mathrm{C}$ via lateral diffusion of $\mathrm{Na}^{+}$ions together with oxide ions into $\mathrm{Co}_{3} \mathrm{O}_{4}$ layers.

There are two features in the present $\mathrm{Na}^{+}$-diffusions. First is the insertion is limited to lateral direction. Insertion of the top layer is not significant. This fact is evidenced by an observation that only periphery of the film was changed into $\mathrm{Na}_{x} \mathrm{CoO}_{2}$ when $\mathrm{CoO}$ film was annealed at $700^{\circ} \mathrm{C}$ for short time $(\sim 5 \mathrm{~min})$. Another is that epitaxial thin film is retained after the $\mathrm{Na}^{+}$-diffusion is completed. In most cases, samples are broken into pieces by diffusion such as intercalation. It is considered that cracking due to $\mathrm{Na}^{+}$-diffusion and crack heal due to solid-state sintering are well-balanced at $600-700^{\circ} \mathrm{C}$ for this material.

Thin film TE devices can be developed by using the R-SPE grown $\mathrm{Na}_{0.83} \mathrm{CoO}_{2}$ epitaxial film. In addition, this $\mathrm{Na}_{0.83} \mathrm{CoO}_{2}$ epitaxial film would be appropriate to study the mechanism of superconductivity for the water containing system, $\mathrm{Na}_{0.35}$ $\mathrm{CoO}_{2}-1.3 \mathrm{H}_{2} \mathrm{O}$. Very recently we have successfully fabricated $\mathrm{Na}_{0.35} \mathrm{CoO}_{2}-1.3 \mathrm{H}_{2} \mathrm{O}$ epitaxial film by oxidation \& hydration of $\mathrm{Na}_{0.8} \mathrm{CoO}_{2}$ epitaxial film grown by the R-SPE. The $\mathrm{Na}_{0.35}$ $\mathrm{CoO}_{2}-1.3 \mathrm{H}_{2} \mathrm{O}$ epitaxial film exhibited superconducting transition at the $T_{\mathrm{c}} \sim 4 \mathrm{~K}$.

\section{Summary}

I reviewed high-quality epitaxial film growth of $\mathrm{InGaO}_{3}$ $(\mathrm{ZnO})_{m}(m=$ integer $), \mathrm{LaCuOCh}(\mathrm{Ch}=\mathrm{S}$ and $\mathrm{Se})$ and $\mathrm{Na}_{x} \mathrm{CoO}_{2}(x \sim 0.8)$, which have natural MQW structure, by reactive solid-phase epitaxy (R-SPE). For the epitaxial film growths of the complex systems with a complicated layered crystal structure, it is essential to form an epitaxial template layer before the film deposition, followed by the thermal annealing of the bilayer films. The layers subsequently deposited on the template layer may be amorphous, polycrystalline or powder, which allows control of the epitaxially grown films in the R-SPE method.

The R-SPE method is considered to be a versatile technique for the epitaxial growth. It is not limited to layered oxides as described above, but applicable to various materials. It is particularly suited to the epitaxial growth of complex oxides with a layered structure.

Acknowledgements These works were performed at Hosono Transparent ElectroActive Materials Project (TEAM), ERATO, Japan Science and Technology Agency (JST). The author gratefully thanks Prof. Hideo Hosono of Tokyo Institute of Technology (Director of TEAM project) and Dr. Masahiro Hirano (Manager of TEAM project) for their endless support. The author also would like to thank Dr. Kenji Nomura and Dr. Hidenori Hiramatsu of TEAM project for their great support to perform the R-SPE work, Prof. Yuichi Ikuhara of the University of Tokyo, Mr. Toshiyuki Suzuki and Ms. Chizuru Honjyo of Japan Fine Ceramics Center (JFCC) for their experimental assistance in HRTEM observation, Prof. Kunihito Koumoto and Mr. Kenji Sugiura of Graduate School of Engineering, Nagoya University for their helpful discussion.

\section{References}

1) Ohta, H., Nomura, K., Orita, M., Hirano, M., Ueda, K., Suzuki, T., Ikuhara, Y. and Hosono, H., Adv. Funct. Mater., Vol. 13, pp. 139-144 (2003).

2) Vossen, J. L. and Kern, W., “Thin Film Processes," Academic Press, New York (1978).

3) Suntola, T. and Simpson, M., "Atomic Layer Epitaxy," Chapman and Hall, New York (1990).

4) Chrisey, C. B. and Hubler, G. K., "Pulsed Laser Deposition of Thin Films," John Wiley \& Sons, New York (1994).

5) "Current Topics in Materials Science," Vol. 3, Ed. by Kaldis, E. (1979) pp. 154-154.

6) Nomura, K., Ohta, H., Ueda, K., Orita, M., Hirano, M. and Hosono, H., Thin Solid Films, Vol. 411, pp. 147-151 (2002).

7) Hiramatsu, H., Ueda, K., Ohta, H., Orita, M., Hirano, M. and Hosono, H., Appl. Phys. Lett., Vol. 81, pp. 598-600 (2002).

8) Ohta, H., Mizoguchi, H., Hirano, M., Narushima, S., Kamiya, T. and Hosono, H., Appl. Phys. Lett., Vol. 82, pp. 823-825 (2003).

9) Ohta, H., Kim, S.-W., Ohta, S., Koumoto, K., Hirano, M. and Hosono, H., Cryst. Growth Des., Vol. 5, pp. 25-28 (2005).

10) Kasper, H., Z. Anorg. Allg. Chem., Vol. 349, pp. 113-123 (1967).

11) Kimizuka, N. and Takayama, E., J. Solid State Chem., Vol. 40, pp. 109-116 (1981). 
12) Cannard, P. J. and Tilley, R. J. D., J. Solid State Chem., Vol. 73, pp. 418-426 (1988).

13) Kimizuka, N., Mohri, T. and Nakamura, M., J. Solid State Chem., Vol. 81, pp. 70-77 (1989).

14) Kimizuka, N., Isobe, M., Nakamura, M. and Mohri, T., J. Solid State Chem., Vol. 103, pp. 394-402 (1993).

15) Isobe, M., Kimizuka, N., Nakamura, M. and Mohri, T., Acta Cryst., Vol. C50, pp. 332-336 (1994).

16) Li, C., Bando, Y., Nakamura, M., Onoda, M. and Kimizuka, N., J. Solid State Chem., Vol. 139, pp. 347-355 (1998).

17) Pitschke, W. and Koumoto, K., Powder Diffr., Vol. 14, pp. 213-218 (1999)

18) Phillips, J. W., Cava, R. J., Thomas, G. A., Cater, S. A., Kwo, J., Siegrist, T., Krajewski, J. J., Marchall, J. H., Peak, W. F., Jr. and Papkine, D. H., Appl. Phys. Lett., Vol. 67, pp. 2246-2248 (1995).

19) Hiramatsu, H., Seo, W. S. and Koumoto, K., Chem. Mater., Vol. 10, pp. 3033-3039 (1998).

20) Naghavi, N., Rougier, A., Marcet, C., Guery, C., Leriche, J. B. and Trascon, J. M., Thin Solid Films, Vol. 360, pp. 233-240 (2000).

21) Ohta, H., Seo, W. S. and Koumoto, K., J. Am. Ceram. Soc., Vol. 79, pp. 2193-2196 (1996).

22) Ohta, H., Tanji, H., Orita, M., Hosono, H. and Kawazoe, H., Mater. Res. Soc. Symp. Proc., Vol. 570, pp. 309-312 (1999).

23) Orita, M., Ohta, H., Hirano, M., Narushima, S. and Hosono, H., Philos. Mag., B 81, pp. 501-515 (2001).

24) Nomura, K., Ohta, H., Ueda, K., Kamiya, T., Orita, M., Hirano, M., Suzuki, T., Honjyo, C., Ikuhara, Y. and Hosono, H., J. Appl. Phys., Vol. 95, pp. 5532-5539 (2004).

25) Nomura, K., Kamiya, T., Ohta, H., Ueda, K., Hirano, M. and Hosono, H., Appl. Phys. Lett., Vol. 85, pp. 1993-1995 (2004).

26) Nomura, K., Ohta, H., Ueda, K., Kamiya, T., Hirano, M. and Hosono, H., Science, Vol. 300, pp. 1269-1272 (2003).

27) Ohta, H. and Hosono, H., Mater. Today, Vol. 7, pp. 42-51 (2004).

28) Kawazoe, H., Yasukawa, M., Hyodo, H., Kurita, M., Yanagi, H. and Hosono, H., Nature (London), Vol. 389, pp. 939-942 (1997).

29) Kudo, A., Yanagi, H., Hosono, H. and Kawazoe, H., Appl. Phys. Lett., Vol. 73, pp. 220-222 (1998).

30) "Transparent Conducting Oxides," Ed. by Ginley, D. S. and Bright, C., MRS Bull., 25 (2000) Articles therein.

31) Yanagi, H., Hase, T., Ibuki, S., Ueda, K. and Hosono, H., Appl. Phys. Lett., Vol. 78, pp. 1583-1585 (2001).

32) Ueda, K., Hase, T., Yanagi, H., Kawazoe, H., Hosono, H., Ohta, H., Orita, M. and Hirano, M., J. Appl. Phys., Vol. 89, pp. 1790-1793 (2001).

33) Ueda, K., Inoue, S., Hirose, S., Kawazoe, H. and Hosono, H., Appl. Phys. Lett., Vol. 77, pp. 2701-2703 (2000).

34) Palazzi, M., C. R. Acad. Sci. Paris, Vol. 292, pp. 789-792 (1981).

35) Zhu, W. J., Huang, Y. Z., Dong, C. and Zhao, Z. X., Mater. Res. Bull., Vol. 29, pp. 143-147 (1994).

36) Ueda, K., Hiramatsu, H., Ohta, H., Hirano, M., Kamiya, T. and Hosono, H., Phys. Rev. B, Vol. 69, Art. No. 155305 (2004).

37) Hiramatsu, H., Ueda, K., Ohta, H., Hirano, M., Kamiya, T. and Hosono, H., Appl. Phys. Lett., Vol. 82, pp. 1048-1050 (2003).

38) Ueda, K., Inoue, S., Hosono, H., Sarukura, N. and Hirano, M., Appl. Phys. Lett., Vol. 78, pp. 2333-2335 (2001).

39) Hiramatsu, H., Ueda, K., Takafuji, K., Ohta, H., Hirano, M., Kamiya, T. and Hosono, H., J. Appl. Phys., Vol. 94, pp. 5805-5808 (2003).

40) Kamioka, H., Hiramatsu, H., Ohta, H., Hirano, M., Ueda, K., Kamiya, T. and Hosono, H., Appl. Phys. Lett., Vol. 84, pp. 879-881 (2004)

41) Ueda, K. and Hosono, H., J. Appl. Phys., Vol. 91, pp. 4768-4770 (2002)

42) Hiramatsu, H., Ohta, H., Suzuki, T., Honjyo, C., Ikuhara, Y. Ueda, K., Kamiya, T., Hirano, M. and Hosono, H., Cryst. Growth. Des., Vol. 4, pp. 301-307 (2004).

43) Hiramatsu, H., Ueda, K., Ohta, H., Kamiya, T., Hirano, M. and Hosono, H., Appl. Phys. Lett. (in press).

44) Fouassier, C., Matejka, G., Reau, J. M. and Hagenmuller, P., J. Solid State Chem., Vol. 6, pp. 532-537 (1973).

45) Terasaki, I., Sasago, Y. and Uchinokura, K., Phys. Rev. B, Vol. 56, pp. 12685-12687 (1997).

46) Wang, Y., Rogado, N. S., Cava, R. J. and Ong, N. P., Nature, Vol. 423, pp. 425-428 (2003).

47) Terasaki, I., Physica B, Vol. 328, pp. 63-63 (2003) and references therein.

48) Motohashi, T., Naujalis, E., Ueda, R., Isawa, K., Karppinen, M. and Yamauchi, H., Appl. Phys. Lett., Vol. 79, pp. 1480-1482 (2001).

49) Fujita, K., Mochida, T. and Nakamura, K., Jpn. J. Appl. Phys., Vol. 40, pp. 4644-4647 (2001).

50) Takada, K., Sakurai, H., Takayama-Muromachi, E., Izumi, F., Dilanian, R. A. and Sasaki, T., Nature, Vol. 422, pp. 53-55 (2003).

51) Schaak, R. E., Klimczuk, T., Foo, M. L. and Cava, R. J., Nature, Vol. 424, pp. 527-529 (2003).

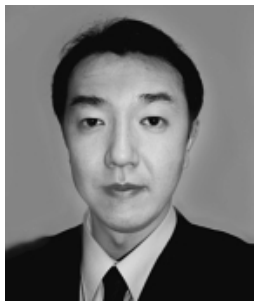

\section{Hiromichi Ohta}

Education

Saitama University, Department of Applied Chemistry, B. E., 1994/Nagoya University, Department of Applied Chemistry, M. E., 1996/Tokyo Institute of Technology, Department of Innovative and Engineered Materials, D. E., 2001

Thesis: Optoelectronic Device Application of Transparent Oxide Semiconductors

Experience

Associate Professor, Nagoya University (Department of Applied Chemistry) 2003-present/ Postdoctoral researcher, HOSONO Transparent ElectroActive Materials Project, ERATO, JST 1999-2003/R\&D Engineer, HOYA Co. (Development of Transparent Conducting Oxides) 1998-2003/Engineer, SANYO Electric Co. (Development of Li-ion battery) 19961997 